\title{
FE modeling of delamination growth in interlaminar fracture specimens
}

\author{
Vyacheslav N. Burlayenko ${ }^{1,2}$, Tomasz Sadowski ${ }^{2}$ \\ ${ }^{1}$ National Technical University 'KhPI', Department of Applied Mathematics, \\ 61002 Kharkov, Frunze 21 Str., Ukraine, e-mail: v.burlayenko@pollub.pl \\ ${ }^{2}$ Lublin University of Technology, Department of Solid Mechanics, \\ 20-618 Lublin, Nadbystrzycka 40 Str., Poland, e-mail: t.sadowski@pollub.pl
}

\begin{abstract}
Interlaminar fracture specimens like Double Cantilever Beam (DCB), End Notched Flexural (ENF), Single Leg Bending (SLB) etc. are widely used for studying the interlaminar toughness of composite laminates. The aim of this paper is to analysis delamination specimens within the framework of a meso-level damage modeling of composite laminates. In this case interlaminar interface is assumed as a damageable homogeneous layer between adjacent layers of the specimen bulk material. The degradation of the interlaminar connection can be taken into account by means either of an appropriate damage initiation criterion and damage evolution law or using fracture mechanics approach. Onset and growth of the delamination pre-existing crack in the fracture specimens are simulated by using both modeling possibility within commercial finite element code ABAQUS ${ }^{\mathrm{TM}}$. Comparisons between numerical predictions of used different finite element models as well as available experimental data have been performed.
\end{abstract}

Key words: interlaminar fracture specimens, delamination, ABAQUS, finite element predictions.

\section{Introduction}

Nowadays the use of composite materials is growing rapidly around the world. The composite materials are fallen into structural materials with tailoring facilities for creating high performance structures. This their ability makes such materials more attractive for using in different engineering applications before traditional structure materials such as metals or concrete. For instance, the composite materials have been widely used as structural elements of aircrafts, airspace and transport vehicles, and marine vessels as well as structural materials in civil engineering and sport inventories, etc. However, because composite materials consist technologically of different constituent materials they exhibit more sensitivity to damage than conventional ones.

One of the most frequently encountered problems in composite layered materials is interface cracking or the loss of cohesion between layers, known as delamination phenomenon. The interlaminar deterioration may occur due to a variety of reasons, such as high in-service loading and aggressive conditions, low energy impact, manufacturing defects or high stress concentration at the geometrical or 
material discontinuities (e.g. free edge effects) [1]. This damage mode is particularly important for structural integrity of whole composite structure. Because, delamination leads to the drastic reduction of bending stiffness of composite structure and promotes local buckling phenomenon [2]. With delamination growth the load carrying capacity of a delaminated structure is further reduced and may eventually cause failure. Thus, the safety of using as a structural material of layered composites is strongly influenced by the quality of the adhesion between their different layers. To be able to guarantee the advantages of structures made of laminate or sandwich composite materials it is necessary that this critical damaging mechanism as well as material characteristics corresponding to fracture toughness of materials were carefully studied and analyzed.

Due to the intrinsic complexities of delamination phenomenon regarding its singular nature, quantitative assessments of the delamination effects on the strength and lifetime of laminated structures are difficult as well as universal delamination failure criterions has not yet been established. Analytical efforts and their numerical implementations to date have only attempted to quantify the effects of idealized delaminations. Experimental data of the fracture test specimens designed and loaded so to induce delamination growth close to those idealized situations are used for these purposes. Then, numerical simulations of the interlaminar fracture tests may be considered as being useful, at least, for two reasons. The first one, the numerical simulations or virtual testing replace many expensive and time consuming experiments. In this case, it is the necessity to test the numerical model in situation in which experimental results are easily available. The second one is connected with the necessity to build new analytical models, and then the numerical model is compared to experimental results for the purpose of fitting the correct parameters of these models.

In the present paper, numerical simulations are conducted to study the delamination growth in fracture test specimens such double cantilever beam and single le bending that are usually applied for extracting of fracture parameters. Twoand three-dimensional finite element (FE) analyses with ABAQUS ${ }^{\mathrm{TM}}$ code [3] are carried out. Both the virtual crack closure technique that has been implemented in ABAQUS $^{\mathrm{TM}}$ as package VCCT for ABAQUS ${ }^{\mathrm{TM}}$ version 1.2-3 and the modeling with cohesive elements available in ABAQUS ${ }^{\mathrm{TM}}$ element library are applied to predict delamination growth in the initially delaminated composite laminate specimens. Delamination growths from finite element analyses are compared between different finite element models and with experiment data that are available from literature.

\section{Interlaminar fracture tests}

Over the past two decades it has become common practice to characterize the resistance to delamination using fracture mechanics approach. In the context of fracture mechanics, test methods have evolved for measuring the interlaminar fracture toughness in terms of a critical value of strain energy release rate (ERR), $G_{C}$, associated with delamination onset and growth. A complete description of interlaminar fracture toughness requires characterization of three pure fracture modes, opening mode I, sliding shear mode II, scissoring shear mode III and their combinations (Fig. 1). 
a)

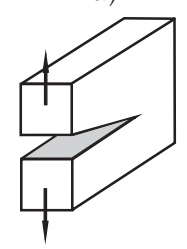

b)

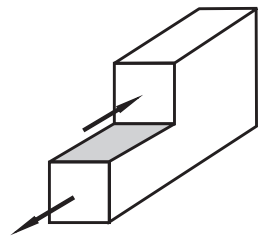

c)

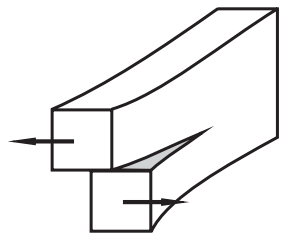

Fig. 1. Crack growth modes: a) I - opening, b) II - sliding, c) III - scissoring.

The strain energy release rates (fracture toughness parameters) in all the three modes are usually used in single-mode criteria or combined in a mixed-mode criterion to determine the onset of crack propagation, and these generally require curvefitting parameters taken from experimental tests. A number of delamination specimens have been proposed in order to identify fracture parameters in pure mode I, mode II or in mixed-mode situation. The near pure mode I fracture occurs in the Double Cantilever Beam (DCB) (Fig. 2a). Hence, the opening ERR $G_{I C}$, can be obtained. The End Notched Flexural (ENF) test configuration is preferred for measuring of pure Mode II ERR, $G_{\text {IIC }}$ (Fig. 2b). From results of these pure mode loadings, the critical Mode I and Mode II fracture toughness parameters can be obtained according to the following formula:

$$
G=\frac{P^{2}}{2 B} \frac{d C}{d a}
$$

where $P, B$ and $a$ denote the applied load, the specimen width and the crack length, respectively, and $C$ is the compliance (load divided by displacement). After compliance calibration (so-called compliance method, e.g. [4]) the formulae for the $G_{I C}$ and $G_{I I C}$ can be eventually derived.

a)

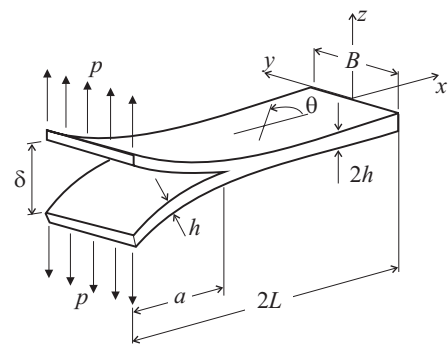

b)

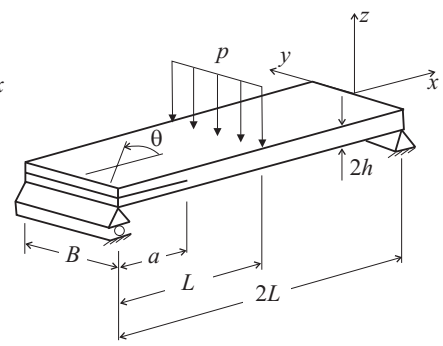

c)

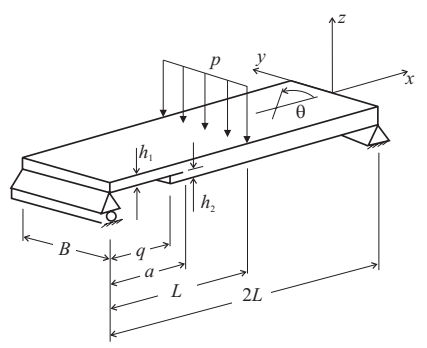

Fig. 2. Fracture test specimens: a) DCB, b) ENF, c) SLB.

In order to generalize failure criterion on the delamination resistance under combined loadings the mixed-mode tests are needed. The mixed-mode I and II occurs, for instance, in the Single Leg Bending (SLB) specimen (Fig. 2c). In order to separate of total value of ERR into sum of each mode the finite element simulation is necessary. Then, with the critical applied load measured from the test as the input information for FE analysis, the ERR of each fracture mode can be computed separately. Several specimens have also suggested for measuring of the Mode III ERR, $G_{I I I C}$, the Split Cantilever Beam (SCB) is one of them. Nevertheless, an interaction mixed-mode I, II and III criterion has not yet been established [5]. 


\section{Modeling}

Two kinds of approach are now used to study delamination behavior of layered composites. The first one uses the conception of Fracture Mechanics. In such approach, delamination growth is predicted when a combination of the components of the energy release rate is equal to, or greater than, a critical value. Techniques such as virtual crack closure technique (VCCT) (Irwin [6], Rybicki and Kanninen [7], Raju [8], Zou et al. [9], Krueger [10]), J-integral method (Rice [11]), virtual crack extension (Hellen [12]) and stiffness derivative (Parks [13]) have often been used to calculate the ERR. The second one is developed within the framework of Damage Mechanics. These models are based on the cohesive zone conception in which the interface enclosing the delamination is modeled by a damageable material. Then, delamination is started when a damage variable reaches its maximum value (Allix et al. [14], Allix and Corigliano [15], Schellekens and de Borst [16], Benzeggagh and Kenane [17], Mi et al. [18], Chen et al. [19], Alfano and Crisfield [20], Camanho et al. [21], Goyal-Singhal et al. [22]). Because, in finite element code ABAQUS ${ }^{T M}$ has been implemented the virtual crack closure technique as an add-on capability to ABAQUS/Standard v.6.6 and the cohesive zone approach as $2 \mathrm{D}$ or 3D cohesive elements, these both approaches will be considered below more explicitly.

\subsection{Virtual crack close technique}

When other material non-linearities can be neglected, methods based on Linear Elastic Mechanics have been proven to be effective in delamination modeling. In this case, delamination can be considered as a crack in the bond between two layers and its propagation can be treated as crack growth adopting the concepts of Fracture Mechanics. Therefore, in order to analyze the delamination growth of laminated structures it is necessary to determine the stress fields of delamination front. However, the stress of the delamination front is singular, whereas the ERR, which indicates intensity of stress fields along delamination front, is a finite value. The virtual crack closure technique is one of the most commonly applied methods for determining the components of the strain energy release rate along a crack front. The VCCT approach was proposed by Rybicki and Kanninen [7] and is based on two assumptions: 1) Irwin's assumption that the energy released in crack growth is equal to the work required to close the crack to its original length, and 2) that crack growth does not significantly alter the state at the crack tip (self-similarity state). For example, Fig. 3a illustrates the similarity between crack extension from $i$ to $j$ and crack closure at $j$.

Then, assuming that the crack closure is governed by linear elastic behaviour, the energy to close the crack and, consequently, the energy to open the crack, is calculated from the following equations:

$$
-\frac{1}{2} \frac{F_{j} \Delta U_{i}}{\Delta A}=G_{I}, \quad \Delta A=\delta a b
$$

where $F_{i}, \Delta U_{i}, \delta a, B$ and $G_{I}$ denote node reaction force at $j$, displacement between released nodes at $i$, crack extension as the length of the element at the crack front, the width and the energy release rate. 
Fig. $3 b$ illustrates the use of (2) in the case pure Mode I loading. Then, nodes 2 and 5 will start to release when is true the following inequality (crack growth criterion):

$$
-\frac{1}{2} \frac{F_{v, 2,5} v_{1,6}}{b d}=G_{I} \geq G_{I C}
$$

where $G_{I C}$ is the Mode I fracture toughness parameter (critical ERR).

a)

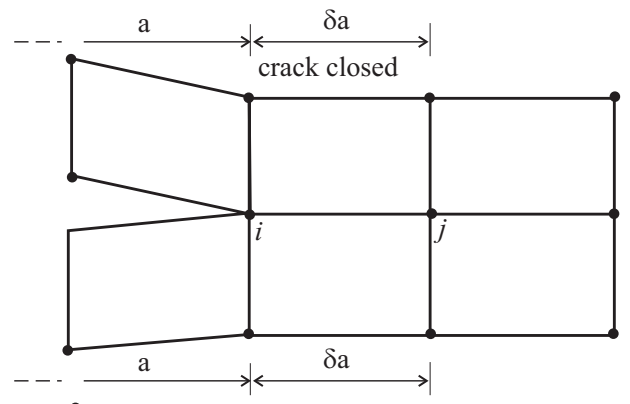

b)
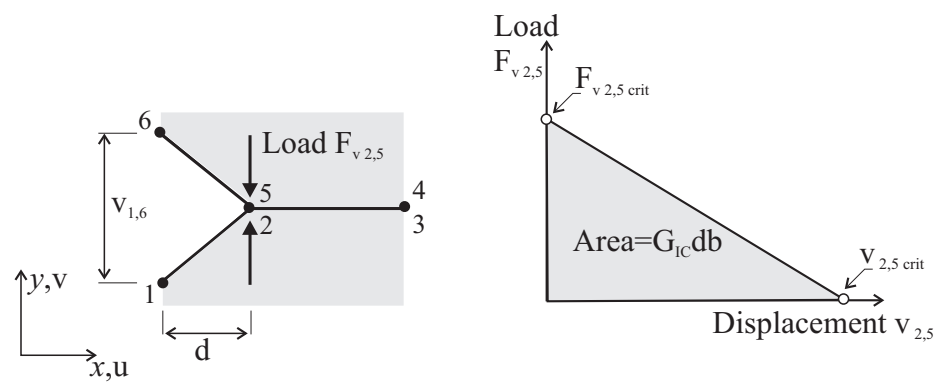

Fig. 3. VCCT approach for pure Mode I: a) crack extension and closure, b) crack growth criterion.

Similar arguments and equations can be written in two dimensions for Mode II and for three-dimensional crack surfaces including Mode III. In the general case involving Mode I, II, and III a node at the crack tip will separate when the equivalent strain energy release rate at the crack tip exceeds the critical strain energy release rate for the bond or the material. That is, the crack extends when $G_{e q} \geq G_{e q C}$, where $G_{e q}$ is the equivalent strain energy release rate at a node, and $G_{e q C}$ is the critical equivalent strain energy release rate calculated based on the some mixed-mode criterion [3]. It should be noted, that the use of VCCT is advantageous as it allows the strain energy release rates to be determined with simple equations from a single (FE) analysis [8], but pre-existing of the initially debonded surfaces along a predefined delamination 
front is compulsory. Moreover, to date, the VCCT for ABAQUS ${ }^{\mathrm{TM}}$ does not support 3D models with contact pairs involving higher-order underlying elements and is confined by static, quasi-static and coupled thermal-stress analyses.

\subsection{Cohesive crack model}

Some difficulties of the implementation of the VCCT into FE codes can to be overcome by using cohesive zone approach within a so-called cohesive element. Cohesive models offer the advantages of incorporating both initiation and growth of delamination in such a way that the damage is initiated by using a strength criteria and the final separation is governed by fracture mechanics parameters. All proposed now cohesive-zone models start from the assumption that one or more interfaces can be defined, where delamination propagation is allowed by the introduction of a possible discontinuity in the displacement field. The interface can be deduced a priori by means of physical observations. Then, considering delamination as a progressive loss of cohesion between adjacent layers of solid, it can be modeled as a deterioration of the interlaminar connection between the layers.

In finite element method cohesive zone models is implemented as interface (cohesive) elements which are compatible with regular solid finite elements. In two dimensions, the cohesive interface elements are composed of two line elements separated by a thickness (Fig. 4a). In three dimension problems they consist of two surfaces separated by a thickness (Fig. 4b). The relative motion of the bottom and top parts of the cohesive element measured along the thickness direction represents opening or closing of the interface. And, the relative motion of theses parts with respect to the element mid-plane is qualified as the transverse shear behaviour of the cohesive element. The stretching and shearing of the element mid-plane are associated with membrane strains [3].

a)

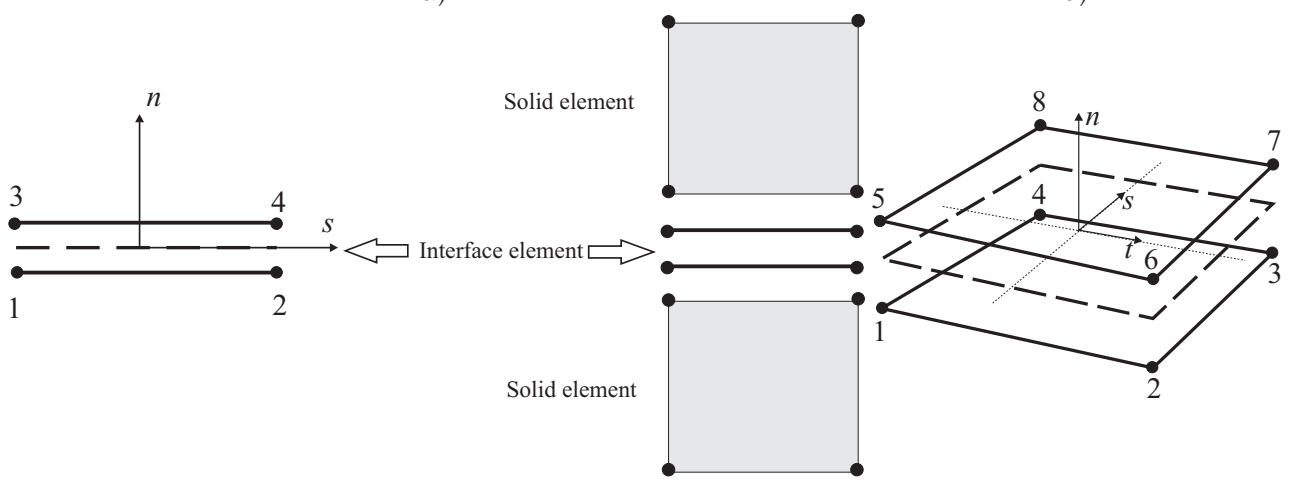

Fig. 4. Schematics of cohesive elements: a) 2D 4-noded, b) 3D 8-noded.

The constitutive response of theses elements depends on the specific application and is based on certain assumptions about the stress strain states that are appropriate for each application area. The nature of the delamination phenomenon, as was above mentioned, may be modeled based on a traction-separation description of the interface. Originally the traction-separation model in ABAQUS ${ }^{\mathrm{TM}}$ assumes linear elastic behaviour. It is written in terms of an elastic constitutive tensor $\mathbf{K}^{0}$ that 
relates the nominal stresses (traction vector) $\tau^{T}=\left(\tau_{n}, \tau_{s}, \tau_{t}\right)$ to the nominal strains (opening displacement vector) $\Delta^{T}=\left(\delta_{n}, \delta_{s}, \delta_{t}\right)$ across the interface. Damage of the traction-separation response is defined within the general framework of Continuum Damage Mechanics used for conventional materials. According to that, the combination of several damage mechanisms acting simultaneously on the same material are possible and each failure mechanism consists of a damage initiation criterion, a damage evolution law, and a propagation condition. Fig. 5 shows a graphic interpretation of a simple bilinear traction-separation law written in terms of the effective traction $\tau$ and effective opening displacement $\delta$.

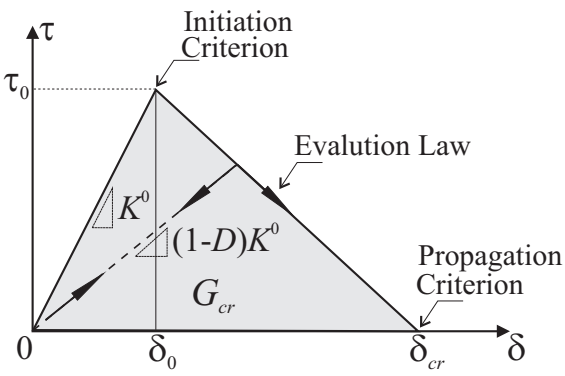

Fig. 5. Bilinear traction - separation constitutive law.

It is obviously that the relationship the effective traction and effective opening displacement is defined by three parameters, two of which uniquely define the fracture process. These parameters are the peak traction (local strength of the material, $\left.\tau_{0}\right)$, a characteristic opening displacement at fracture $\left(\delta_{c r}\right)$, and the energy needed for opening the crack (area under the traction-displacement curve, $G_{c r}$ ) (Fig. 5). Several damage initiation criteria are available in ABAQUS ${ }^{\mathrm{TM}}$ code [3]. Once the corresponding initiation criterion is reached, the specified damage evolution law will describe the rate at which the material stiffness is degraded. A scalar damage variable $D$ $(0 \leq D \leq 1)$ represents the overall damage in the material and captures the combined effects of all active degradation mechanisms. To describe the damage evolution in general case under a combination of normal and shear deformations across the interface, the different mode-mix laws defined in terms of energies and tractions are suggested by ABAQUS ${ }^{\mathrm{Tm}}[17,21]$. When the overall damage variable reaches its limit $D_{\max }$ at all of its material points the cohesive element can be removed that corresponds to complete fracture of the interface between layers and is considered as delamination propagation. Interpenetration of the two adjacent layers after complete debonding is prevented by modeling of contact properties.

\subsection{Some numerical issues}

In non-linear numerical analyses is usually solved by directly applying an interactive procedure, such as the Newton-Raphson method, in which the load is a known quantity and displacement vector is only unknown. The modeling of progressive damage is generally characterized by anisotropy, softening and irreversibility. These features originate the main difficulties connected with a convergence in an implicit solution procedure. Moreover, non-uniqueness of solution and localization problems can completely falsify the results. Several methods are available in ABAQUS ${ }^{T M}$ to help avoid these problems. Using viscous regularization allows improving the 
convergence for theses kinds of problems. A useful method to avoid divergence due to local instabilities is using automatic stabilization. Both the dissipation energy and damping factor magnitudes can be used. Finally, nondefault solution control parameters can be used to control non-linear equation solution accuracy and time increment adjustment a well as to activate the line search technique [3].

\section{Numerical predictions}

The numerical simulation of delamination processes assumes that the potential surface of separation corresponding to the interlaminar interface is a priori known. Hence, in the case of the VCCT approach, FE modeling is made based on the introduction of double nodes across the potential debonding surface. The modeling with cohesive elements assumes the discretization of the defined interface by compatible cohesive elements, the nodes of which coincide with nodes of solid elements or are tied to sides of solid elements of adjacent layers of bulk material.

\subsection{Double Cantilever Beam specimen model}

The DCB specimen has a span $2 L$ of $228.6 \mathrm{~mm}$ and a rectangular cross-section with width $B$ of $25.4 \mathrm{~mm}$ and height $2 h$ of $10.15 \mathrm{~mm}$ (Fig. 2a). This specimen consists of two identical adherents (arms or legs), with the Young's modulus $E=55.158 \mathrm{GPa}$ and Poisson's ratio $v=0.3$ of isotropic bulk material. These adherents are joined by an adhesive layer with the thickness. One end of the beam is fixed, and the other end is loaded with an external force with the same magnitude but opposite direction as shown in Fig. 2a. This self-equilibrated pair of forces was modeled by prescribed displacements $(u=4.064 \mathrm{~mm})$ resulting in an opening (mode I) loading mode. The spatial discretization of the DCB specimen was done for both two dimensional (2D) and three dimensional (3D) models. The 2D model used a finite element mesh of 4-noded bilinear plane strain quadrilateral incompatible mode elements, CPE4I. The 3D model was discretized by 8 -noded solid brick incompatible mode elements, C3D8I, or by 4-noded fully integrated first-order shell elements, S4.

The interface of the potential debonding (Fig. 2a) in VCCT approach was modeled by nodes having same coordinates but belonging to different elements (double nodes) on the upper and lower surfaces of the delaminated interface. Then, the crack propagation was simulated based on the Benzeggagh-Kenane mixed-mode failure criterion with power 1.75 at the given fracture toughness parameters of the interface $\left(G_{I C}=1.2 \mathrm{~N} / \mathrm{mm}, G_{I I C}=G_{I I I C}=6 \mathrm{~N} / \mathrm{mm}\right)$. The cohesive zone approach was realized by embedded into the $2 \mathrm{D}$ mesh of 4 -noded cohesive elements, $\mathrm{COH} 2 \mathrm{D} 4$, and into the 3D mesh of 8-noded cohesive elements, $\mathrm{COH} 3 \mathrm{D} 8$, which are available in ABAQUS ${ }^{\mathrm{TM}}$. The cohesive elements similar as for the VCCT model use to present the bonded part of the DCB while cracked portion (pre-existing crack) between two interfaces did not contain these elements. The cohesive elements had share nodes with adjacent solid elements, presenting the bulk isotropic material. Parameters of the damage initiation criterion and damage evolution law as well as elastic interface constants were specified for the cohesive element to correspond to the debonded features of the interface layer using for crack growth analysis with VCCT. The elastic properties of the cohesive material are specified in terms of the tractionseparation response with stiffness values $E=80 \mathrm{MPa}, G_{1}=80 \mathrm{MPa}$, and $G_{2}=80 \mathrm{MPa}$. 
The maximum nominal strain failure criterion for the given peak values of the nominal strain $\varepsilon_{n}=\varepsilon_{s}=\varepsilon_{t}=9 \times 10^{-7}$ is selected for damage initiation in the cohesive elements and a mixed-mode energy-based damage evolution law based on B-K law criterion is selected for damage propagation. The relevant material data are as follows: $N_{0}=0.8 \mathrm{MPa}, T_{0}=0.8 \mathrm{MPa}, S_{0}=0.8 \mathrm{MPa}$ and $\eta=1$ (the notations from [3]).

a)

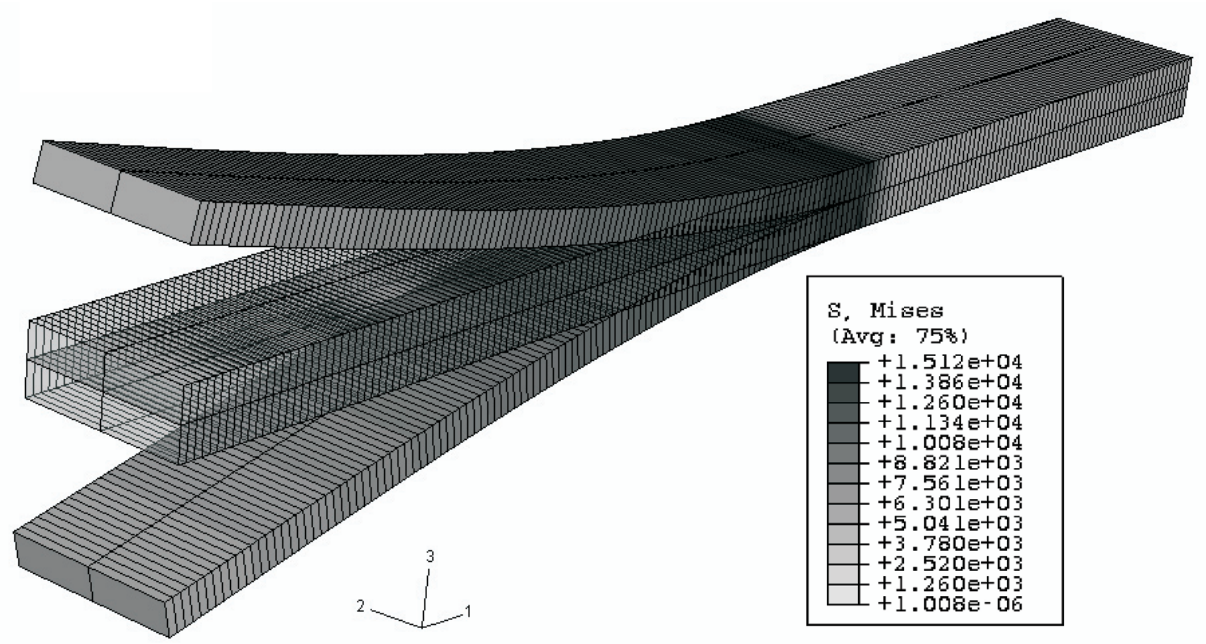

b)

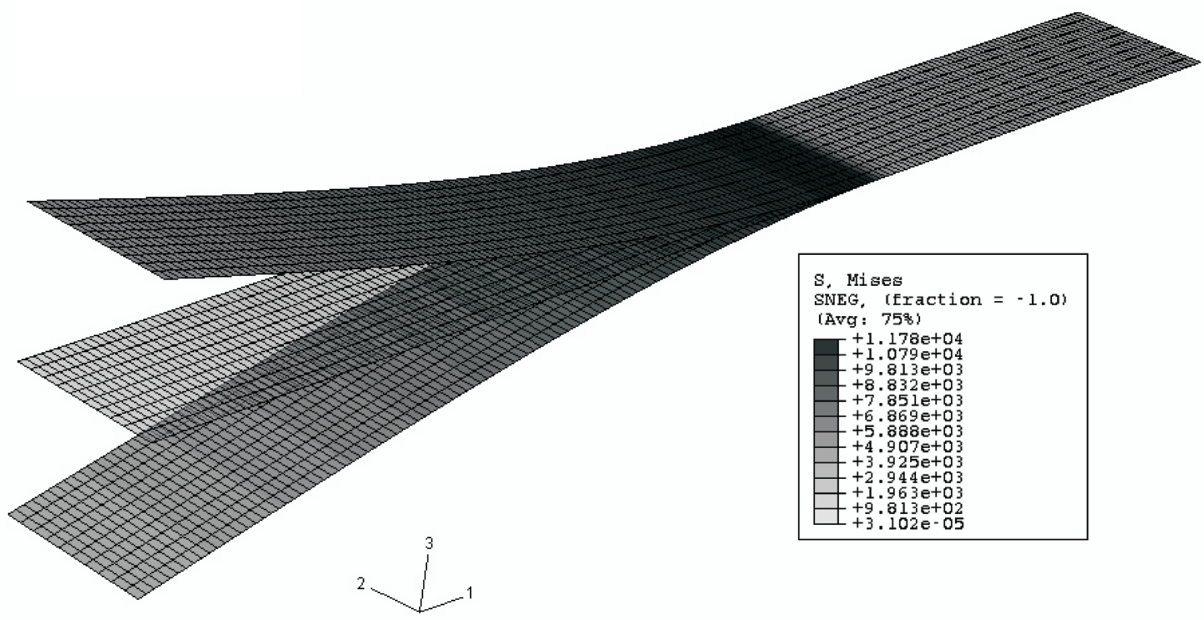

Fig. 6. The deformed shape of the DCB models using: a) solid elements, b) shell elements.

Fig. 6 shows a contour plot of Misses stress that illustrates the debonding growth in the $3 \mathrm{D}$ models of the DCB specimen at the end of the analysis. Load-displacement responses predicted by the different FE models are shown in Fig. 7. Here, the results from the $3 \mathrm{D}$ analyses are compared with the results from $2 \mathrm{D}$ analyses. These analyses are performed using both the VCCT and cohesive elements. From the calculated results the critical force corresponding to debond initiation in the DCB district from theoretical one obtained by Mabson [23] within of 3-7\%. 


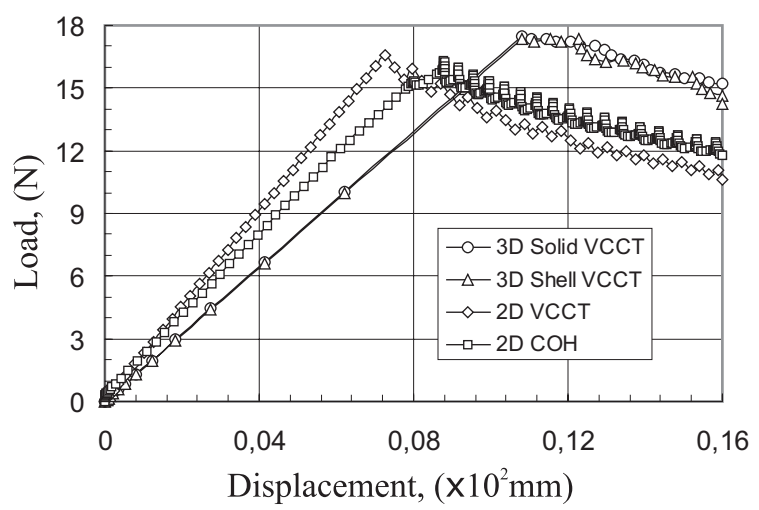

Fig. 7. Load displacement curve.

\subsection{Single Leg Bending specimen model}

The next example illustrates the prediction of debond growth in a single leg bending specimen which usually uses for study of a mixture of opening and shearing loading modes. The calculations were done using VCCT for ABAQUS ${ }^{\mathrm{TM}}$. The geometry parameters of SLB specimen (Fig. 2c) were the following: $2 L=152.4 \mathrm{~mm}$, $B=25.4 \mathrm{~mm}, q=30.48 \mathrm{~mm}, a=37.34 \mathrm{~mm}$. The top part of the specimen was composite of 24 layers with lay-up $\left[45^{\circ} / 0^{\circ} / 45^{\circ} / 0^{\circ} / 45^{\circ} / 0^{\circ} / 45^{\circ} / 0^{\circ} / 45^{\circ} / 0^{\circ} / 45^{\circ} / 0^{\circ}\right]_{s}$ of the total thickness $h_{1}=5.034 \mathrm{~mm}$. The bottom part consisted of 8 layer with lay-up $\left[45 \% 0^{\circ} / 45 \% 0^{\circ}\right]_{S}$ of the total thickness $h_{2}=1.687 \mathrm{~mm}$. The bulk material properties were adopted as the following: $E_{1}=9.1 \mathrm{GPa}, E_{2}=1.49 \mathrm{GPa}, E_{3}=9.1 \mathrm{GPa}, v_{12}=0.51$, $v_{13}=0.06, v_{23}=0.0835, G_{12}=0.4 \mathrm{GPa}, G_{13}=0.7 \mathrm{GPa}$, and $G_{23}=0.4 \mathrm{GPa}$ for material reinforced in the direction of angle $45^{\circ}$, and $E_{1}=2.466 \mathrm{GPa}, E_{2}=1.49 \mathrm{GPa}, E_{3}=2.466 \mathrm{GPa}$, $v_{12}=0.1371, v_{13}=0.7473, v_{23}=0.0835, G_{12}=0.4 \mathrm{GPa}, G_{13}=0.429 \mathrm{GPa}$, and $G_{23}=0.4 \mathrm{GPa}$ for material reinforced in the direction of angle $0^{\circ}$. The $2 \mathrm{D}$ model uses a finite element meshes $24 \times 200$ and $8 \times 160$ of 4 -noded plane strain quadrilateral, incompatible mode elements, CPE4I, for the top and bottom parts, respectively. The 3D models use fully integrated first-order shell elements, S4, and linear brick solid, incompatible mode elements, C3D8I with the composite option for the cross-section description. A displacement $(u=8.128 \mathrm{~mm})$ instead a load is applied on the top part of the specimen at the location shown in Fig. 2c.

Fig. $8 \mathrm{a}, \mathrm{b}$ show the deformed shape of the 3D models at the end of the analyses. Fig. 9 compares the results of load displacement responses from the $2 \mathrm{D}$ and 3D analyses obtained with VCCT for ABAQUS ${ }^{\mathrm{TM}}$ with the results of the analysis performed using interface elements discussed in Mabson [23]. The comparison indicates that the solutions are quite close. 
a)

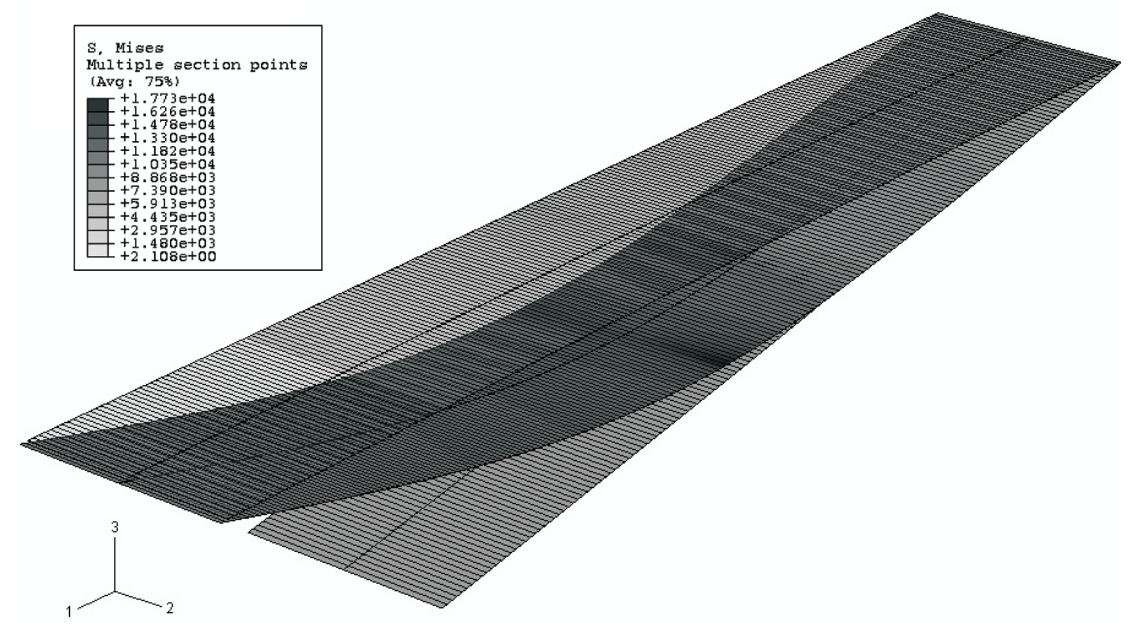

b)

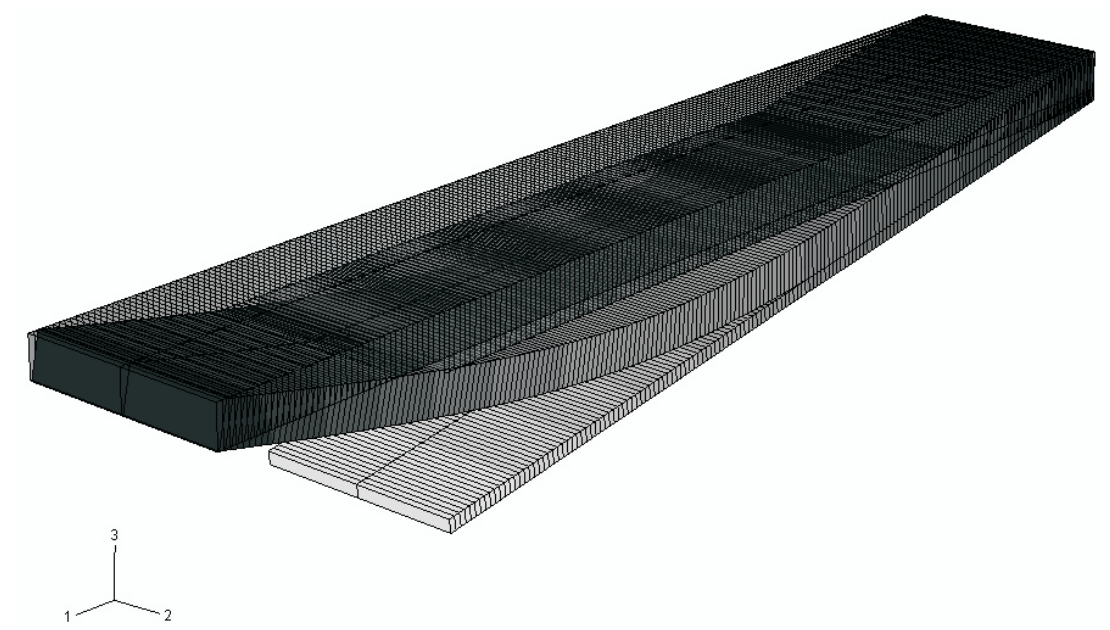

Fig. 8. The deformed configuration: a) 3D model with shell elements, b) 3D model with solid elements.

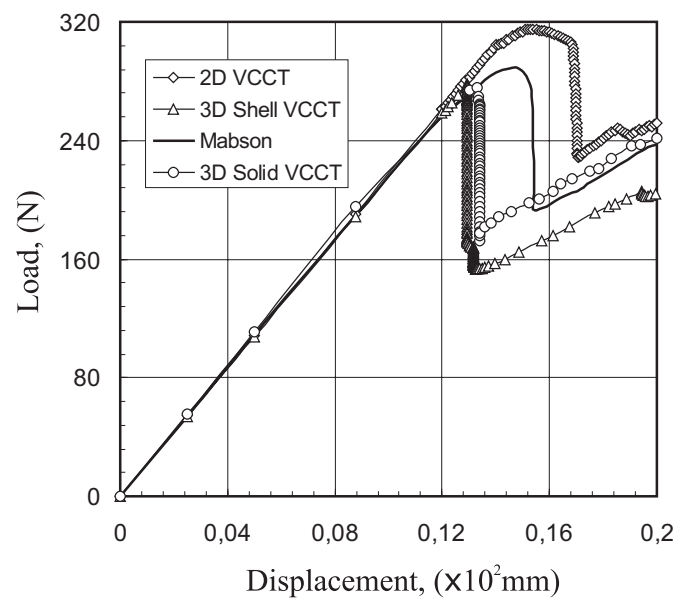

Fig. 9. Load displacement response predictions. 


\subsection{Double cantilever problem II : Alfano-Crisfield problem}

This example verifies and illustrates the use of ABAQUS to predict mixed-mode multi-delamination in a layered composite specimen. Cohesive elements or double nodes are used to represent the bonded interfaces. The problem studied is the one that appears in Alfano [20]. The results presented are compared against the experimental results included in that reference, taken from Robinson [24]. The problem geometry and loading are depicted in Fig. 10: a layered composite specimen, $L=200 \mathrm{~mm}$ long, with a total thickness $H=3.18 \mathrm{~mm}$ and a width $B=20 \mathrm{~mm}$, loaded by equal and opposite displacements in the thickness direction $u=2 \mathrm{~mm}$ at one end. The thickness direction is composed of 24 layers. The model has two initial cracks: the first $a_{1}$ (of length $40 \mathrm{~mm}$ ) is positioned at the midplane of the specimen at the left end, and the second $a_{3}$ (of length $20 \mathrm{~mm}$ ) is located to the right of the first and two layers below. The distance between two initial cracks $a_{2}$ is equal $20 \mathrm{~mm}$.

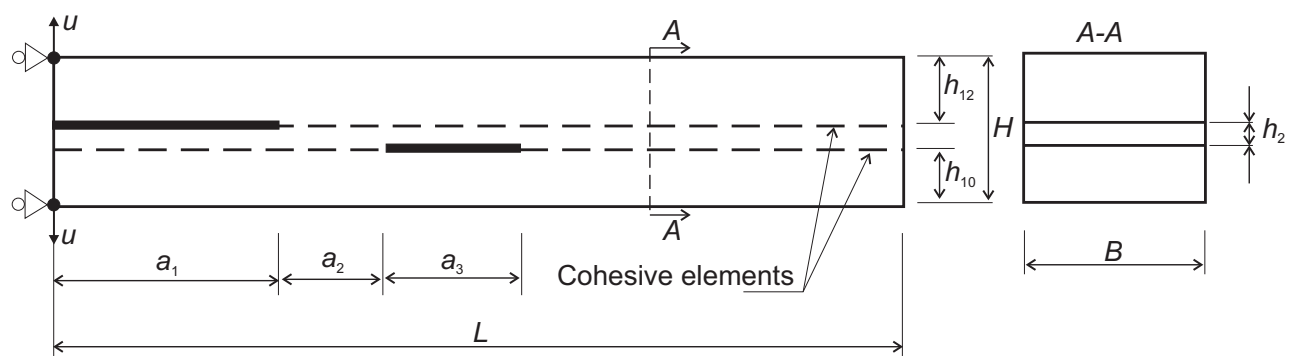

Fig. 10. Model geometry for the Alfano multi-delamination problem.

The Alfano-Crisfield problem is modeled in two dimensions with top part of the specimen consisting of 12 layers (of thickness $h_{12}=1.59 \mathrm{~mm}$ ), the middle section of 2 layers (of thickness $h_{2}=0.265 \mathrm{~mm}$ ) and the bottom part of 10 layers (of thickness $h_{10}=1.325 \mathrm{~mm}$ ). Each part was separately meshed with a mesh of $1 \times 200$ for both the plain strain 2D CPE4I elements and the 3D C3D8I elements. Two debond interfaces are defined, one between the $10^{\text {th }}$ and $11^{\text {th }}$ layers and the other between $12^{\text {th }}$ and $13^{\text {th }}$ layers, counting from the bottom, to identify the potential delamination. For modeling delamination growth the layers of the cohesive elements COH2D4 for 2D discretization or $\mathrm{COH} 3 \mathrm{D} 8$ for 3D one were embedded at these interfaces. The response of the cohesive elements in the model is specified through the cohesive section definition as a "traction-separation" response type. The elastic properties of the cohesive layer material are specified in terms of the traction-separation response with stiffness values $E=850 \mathrm{MPa}, G_{1}=850 \mathrm{MPa}$, and $G_{2}=850 \mathrm{MPa}$. The quadratic traction-interaction failure criterion is selected for damage initiation in the cohesive elements; and a mixed-mode, energy-based damage evolution law based on a power law criterion is selected for damage propagation. The relevant material data are as follows: $N_{0}=3.3 \mathrm{MPa}, T_{0}=7.0 \mathrm{MPa}, S_{0}=7.0 \mathrm{MPa}, G_{I C}=0.33 \times 10^{3} \mathrm{~N} / \mathrm{m}$, $G_{I I C}=0.8 \times 10^{3} \mathrm{~N} / \mathrm{m}, G_{I I I C}=0.80 \times 10^{3} \mathrm{~N} / \mathrm{m}$, and $\eta=1$. For the VCCT approach, using double nodes for representation of debond interfaces, the Benzeggagh-Kenane mixed-mode failure criterion is used to determinate growth of delamination based on the critical fracture toughness of the delamination interfaces. The material data for the bulk material composite are adopted as in [20]: $E_{1}=115.0 \mathrm{GPa}$, $E_{2}=8.5 \mathrm{GPa}, E_{3}=8.5 \mathrm{GPa}, v_{12}=0.29, v_{13}=0.29, v_{23}=0.3, G_{12}=4.5 \mathrm{GPa}, G_{13}=3.3 \mathrm{GPa}$, and $\mathrm{G}_{23}=4.5 \mathrm{GPa}$. 
Fig. 11a shows a contour plot of the Misses stress indicating the growth of delamination in both debond interfaces at the end of the analysis. The plot of the prescribed displacement versus the corresponding reaction force for the delamination problem is presented in Fig. $11 \mathrm{~b}$, where the results calculated on the basis of the different FE models are compared between themselves and with the experimental results obtained in [20]. Both the ABAQUS/Standard and VCCT for ABAQUS ${ }^{\mathrm{TM}}$ results display in the graph. Good agreement is observed between the numerical predictions and the experimental results up to an applied displacement of approximately $20 \mathrm{~mm}$. As seen from Fig 11b, a sharp drop in the reaction force is predicted at the point approximately $10 \mathrm{~mm}$ by the ABAQUS analysis, after which the reaction force values appear to be underpredicted by approximately $30 \%$ when compared to the experimental data. The reason for this deviation, which appears to coincide with the simultaneous propagation of both the cracks, is related to the sudden failure of a relatively large number of cohesive elements in a very short period of time. While the VCCT approach does not has such feature. Because, the release of the critical pair nodes occurs sequentially one-by-one.

a)
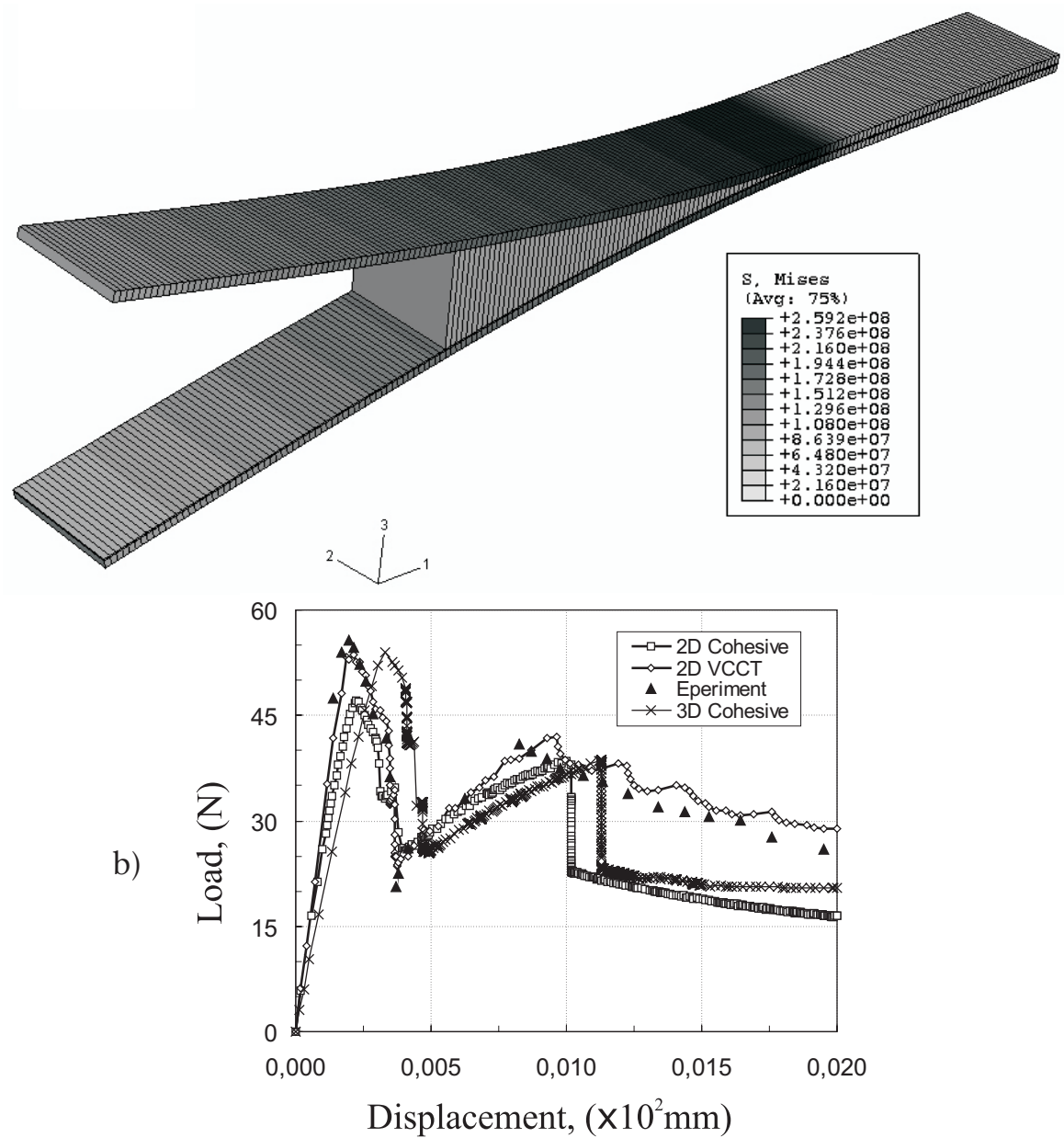

Fig. 11. Prediction results: a) contour plot of Misses stress for the deformed shape of the 3D model, b) load-displacement responses. 


\section{Conclusions}

Finite element analysis was conducted for interlaminar fracture specimens. Those specimens were selected because of them debonding data during testing is available in the literature. Two dimensional and three dimensional models were constructed using commercial code ABAQUS ${ }^{\mathrm{TM}}$. The interlaminar debond was modeled using either cohesive elements that are available in ABAQUS ${ }^{\mathrm{TM}}$ or the virtual crack closure technique that is implemented in ABAQUS ${ }^{\mathrm{TM}}$ by add-on package VCCT for ABAQUS ${ }^{\mathrm{TM}}$. Several example problems were considered and of them results were briefly discussed.

\section{Acknowledgements}

The research is supported by Marie Curie Actions, ToK project - MTKD-CT2004-014058 coordinated by Prof. Tomasz Sadowski at the Lublin University of Technology and funded by European Union within the Sixth Framework Programme. Additional support from Polish Ministry of Science and Higher Education - grant No.65/6.PR UE/2005-2008/7 is also acknowledged.

\section{References}

[1] O'Brien T.K., Characterization of delamination onset and growth in a composite laminate, in: Reifsnider K.I. (Ed.), Damage in Composite Materials, ASTM STP 775. Am. Sot. Testing Mater. (1982): 140-167.

[2] Grigolyuk E.I, Kogan A.A. and Mamay V.I., Deformation problems of laminated structures with delaminations, Izv. Ross. Akad. Nauk., MTT 1 (1994): 6-34.

[3] ABAQUS User Manual. Version 6.6, ABAQUS Inc., Pawtucket, Rhode Island, USA, 2005.

[4] Whitney J.M., Experimental characterization of delamination fracture, in: N.J. Pagano (Ed.), Interlaminar Response of Composite Materials, Composite Materials Series 5 (1989): 111-239.

[5] Li J., Lee S.M., Lee E.W. and O'Brien T.K., Evaluation of the edge crack torsion ECT test for Mode III interlaminar fracture toughness of laminated composites, J. Compos. Technol. Res. 19 (1997): 174-183.

[6] Irwin G.R., Analysis of stresses and strains near the end of a crack transversing a plate, J. Appl. Mech. 24 (1957): 361-366.

[7] Rybicki E.F., Kanninen M.F., A finite element calculation of stress intensity factors by a modified crack closure integral, Eng. Fracture Mech. 9 (1977): 931-938.

[8] Raju, I.S., Calculation of strain-energy release rates with higher order and singular finite elements, Eng. Fracture Mech. 38 (3) (1987): 251-274.

[9] Zou Z., Reid S.R., Li S., Soden, P.D., Mode separation of energy release rate for delamination in composite laminates using sublaminates, Int. J. Solids Struct. 38 (2001): 2597-2613.

[10] Krueger R., The virtual crack closure technique: history, approach and applications, Applied Mechanical Review ASME 57(2) (2004): 109-142.

[11] Rice J.R., A path independent integral and the approximate analysis of strain concentration by notches and cracks, J. Appl. Mech. 35 (1968): 379-386.

[12] Hellen T.K., On the method of the virtual crack extension, Int. J. Numer. Methods Eng. 9 (1975): 187-207.

[13] Parks D.M., A stiffness derivative finite element technique for determination of crack tip stress intensity factors, Int. J. Fract. 10 (4) (1974): 487-502. 
[14] Allix O., Ladeveze P., Corigliano A., Damage analysis of interlaminar fracture specimens, Compos. Struct. 31 (1995): 66-74.

[15] Allix O., Corigliano A., Modelling and simulation of crack propagation in mixed-modes interlaminar fracture specimens, Int. J. Fract. 77 (1996): 111-140.

[16] Schellekens J.C.J., de Borst R., A nonlinear finite-element approach for the analysis of mode-I free edge delamination in composites, Int. J. Solids Struct. 30(9) (1993):1239-53.

[17] Benzeggagh M.L., Kenane M., Measurement of Mixed-Mode Delamination Fracture Toughness of Unidirectional Glass/Epoxy Composites with Mixed-Mode Bending Apparatus, Compos. Science and Technol. 56 (1996): 439-449.

[18] Mi U., Crisfield M.A., Davies G.A.O., Progressive delamination using interface elements, J. Compos. Mater. 32 (1998): 1246-1272.

[19] Chen J., Crisfield M.A., Kinloch A.J., Busso E.P., Matthews F.L., Qiu Y., Predicting progressive delamination of composite material specimens via interface elements, Mech. Compos. Mater. Struct. 6 (1999): 301-317.

[20] Alfano G., Crisfield M.A., Finite element interface models for the delamination analysis of laminated composites: mechanical and computational issues, Int. J. Numer. Methods Engng. 77(2) (2001): 111-170.

[21] Camanho P.P., Dávila C.G., de Moura M.F., Numerical simulation of mixed-mode progressive delamination in composite materials, J. Compos. Mater. 37(16) (2003): 1415-1438.

[22] Goyal-Singhal V., Johnson E.R., Da'vila C.G., Irreversible constitutive law for modeling the delamination process using interfacial surface discontinuities, Compos. Struct. 64 (2004): 91-105.

[23] Mabson G., Fracture Interface Elements, 46th PMC General Session of Mil-17 (Composites Materials Handbook) Organization, Charleston, SC, 2003.

[24] Robinson P., Besant T., Hitchings D., Delamination Growth Prediction Using a Finite Element Approach, 2nd ESIS TC4 Conference on Polymers and Composites, Les Diablerets, Switzerland, 1999. 